\title{
Formulation and Characterization of Composite Propellants from Cassava Stem and Millet Stalk
}

\author{
OA Babatunde, Dr. Hassan, MM Namadi
}

\begin{abstract}
Cassava stem and millet stalks were use as plant biomass in the formulation of composite solid propellant.The sequence used in the formulation is in the following order; Ammonium nitrate, biomass (Carbon), Sulphur, Starch and gum arabicas binders in ratio A:B:C:D of 80:16:2:2 (Cohen, 1997), 65:20:12:3 (Tenny, 1998) and 85:10:4:1(proposed ratio) by mechanical means using mortar and pestle. The formulated composite solid propellants were characterized using Fourier Transform Infrared (FTIR), Scanning Electron Microscope (SEM) and Differential Scanning cabrimeter (DSC). The result of the FTIR showed that interaction had occurred between the individual components (the ammonium nitrate, Plant biomass (Carbon), Sulphur, starch and gum arabicbinders). as indicated by the spectral display of C-O stretch, N-O stretch, N-H Stretch, O-H Stretch, $\mathrm{N}=\mathrm{C}=\mathrm{S}$ Stretch. The SEM image also displayed morphology of honey comb, trapezoid, crater and flaky showing the interaction and various shapes and grain sizes despite the use of starch and gum arabicbinders. From the DSC results, the endothermic peaks range from 40-1680C while exothermic peaks range from $184-2500 \mathrm{C}$. The result indicates the burning rate ability of the propellants in space.
\end{abstract}

Index Terms- Biomass, morphology, propellant. Exorthermic.

\section{INTRODUCTION}

Propellants are substances or combination of substances which burn at an extremely rapid rate producing a large volume of gases. These gases are used to accelerate a projectile in the bore of a gun, propel rockets and missiles along their flight paths, launch aircrafts into the air and are also employed to initiate emergency seat ejection system from aircraft ${ }^{1}$.

Composite is a modified double base (CMDB) propellants which constitute nitrocellulose and nitroglycerin base, binder and addition of solids like typical Ammonium Perchlorate and powdered Aluminium; normally used in composite propellants. The Ammonium Per chlorate makes up the oxygen deficit introduced by using nitrocellulose, improving the overall specific impulse. The Aluminum also improves specific impulse as well as combustion stability. High performing propellants such as NEPE-75 used in Trident II D-5 replace most of the Ammonium Per chlorate (AP) with HMX, further increasing specific impulse. The mixing of

OA Babatunde, Department Of Chemistry, Nigerian Defence Academy (Nda) Kaduna

Dr. Hassan, Department Of Chemistry, Nigerian Defence Academy (Nda) Kaduna Name, Phone/ Mobile No., (e-mail: secondauthor@rediffmail.com).

MM Namadi, name, Department Of Chemistry, Nigerian Defence Academy (Nda) Kaduna composite and double base propellant ingredients has become so common as to blur the functional definition of double base propellants. The physical structure of CMDB is somewhat heterogeneous, and the physiochemical properties are intermediate between composite and homogeneous propellants $^{2}$.

All propellants exhibited convenient chemical stability, an acceptable friction and impact sensitivity as well as being remarkably thermal stable, offering the potential for a mild reaction when exposed to aggressions due to fires. Small scale gap tests show relatively low shock to detonation sensitivity which correspond to a 1.3 hazard classification ${ }^{3}$.

From all manufactured Fox7 propellants only the PU-BDNPF/A binder system provided reasonable mechanical properties and thermal stability, although its burn rate is rather too slow. The energetic GAP-BTTN/TMETN binder system has a suitable burn rate of more than $20 \mathrm{~mm} / \mathrm{s}$, but the strength/strain values are insufficient for a free standing grain application. Further improvement will have to be undertaken to prevent failures at high launch loads. With values of $-52^{\circ} \mathrm{C}$ the glass transition temperatures of GAP/NE propellants yield excellent low temperature flexibility, while for BDNPF/A plasticizer formulations the values shifts to inferior temperatures of $-46^{\circ} \mathrm{C}$.

Burn rates increase with the increasing binder energy and higher amounts of AP oxidizer in the formulation. The smokeless Fox7/GAP (without AP) has with $8,3 \mathrm{~mm} / \mathrm{s}$ the lowest combustion velocity measured at $7 \mathrm{MPa}$, followed by the minimum smoke composition containing 20\% AP with $10,9 \mathrm{~mm} / \mathrm{s}$ at $7 \mathrm{MPa}$. PU- and GAP- bonded Fox7propellants with a BDNPF/A plasticizer exhibit lower burn rates, so that they need higher amounts of AP to reach adequate values.

The highest measured burn rate at $7 \mathrm{MPa}$ is $19,3 \mathrm{~mm} / \mathrm{s}$ obtained by the reduced smoke Fox7/AP/GAP/NE formulation containing $42 \%$ AP. A highlight in this investigation and biggest surprise was the dominant plateau-burning behavior of this formulation. Within the pressure range from 7 to $13 \mathrm{MPa}$, the plateau characteristic becomes more pronounced as the AP content in the Fox 7 propellant is between 36 and $42 \%$, however this is accompanied by a higher smoke signature ${ }^{4}$.

\section{MATERIALS AND METHOD}

\section{SAMPLE COLLECTION AND PREPARATION}

The stem for the cassava was obtained from 3 farms one each located on Kaduna - Zaria Road, Kaduna-Abuja Road and along Kaduna- Kujama Roadand the millet stalk was also collected from 3 farms one each located on Gadan Gaya along Kaduna - Jos Road, Kaduna - Zaria Road and along Mando - 
NDA Road on 2 June 2018. The gum arabicwas collected from acacia an tree (acacia segalis) that produces the gummy sap using a knife which is located in Maigatari, Jigawa State and the starch flour was sourced from cassava tubers obtained from the open market on 3 June 2018 The collected cassava tubers werepeeled and then washed to remove dirt. The washed cassava was then grinded into paste with a grinding machine and then kept in a bowl. The grinded cassava powder was sieved using a 20 micro size pores sieve and the was collected into a clean bowl and allowed to settle for 3 hours, decanted and spread on a wide bowl to dry for 24 hours at room temperature. A fine dried powder was obtained and kept in a plastic container and labeled.

\section{Identification and Authentification of Samples}

The collected samples were taken to a botanist in the Department of Biological Sciences NDA Kaduna for identification and authentication where the plants were confirmed and provided with Codes Herbarium Voucher for the identified plants as follows: 1806 as Millet stalk, 1807 as Cassava stem.

\section{Charring of samples}

The collected and prepared samples from cassava stem and millet stalks were charred separately in order to get the charcoal which constitutes mainly carbon (Biomass). The charring was carried out using an air tight Germany Muffle Furnace with Model Number SXL 1006 at $400{ }^{\circ} \mathrm{C}$ for one hour. The prepared samples of the plants were weighed separately to $400 \mathrm{~g}$ and inserted into the crucible having the size of the muffle furnace chamber for charring with a set temperature of $250{ }^{0} \mathrm{C}$ for one hour. The obtained charcoal were then grinded to powdered form separately using mortar and pestle and labeled separately, kept under sealcontainers.Formulation of Propellant

Composite propellant were prepared according Tenny(65:20:12:3) Cohen (80:16:2:2) and proposed (85:10:4:1). Exactly $32.5 \mathrm{~g}$ ammonium nitrate, $10 \mathrm{~g}$ of carbon, $6 \mathrm{~g}$ of sulphur and $1.5 \mathrm{~g}$ of starch were weighed and transferred into motar and mixed thoroughly. The weights of the components was measured and mixed in such away to achieve the Tenny) ${ }^{5}$ ratio of $(65: 20: 12: 3)$

The same procedure was repeated with weights of component to achieve Cohen $)^{6}$ ration of $(80: 16: 2: 2)$ and the proposed ration of $(85: 10: 4: 1)$.

Exactly the same process was repeated for different carbon sources and gum arabic as binder. All the formulated samples prepared were stored in appropriate sample bottles, labeled accordingly and kept for FTIR, SEM and DSC analysis.

\section{Characterization of the Propellants}

The formulated samples were then characterized using Fourier Transform Infrared Spectrometer (FTIR), Scanning Electron Microscope (SEM) and Differential Scanning Calorimeter (DSC).

\section{Fourier Transform Infrared Spectrometer (FTIR)}

The FTIR characterization was carried out using the Agilent Carry FTIR Spectrometer (USA) with model number 630 . Exactly $0.5 \mathrm{~g}$ of the sample was measured separately and fixed in a small cup like holder, one after the other and compressed to pellet which was put on the crystal optical path and clicked on the software to process. The sample alignment was check performing for proper sampling and the coding of the samples. The measurement was clicked and the peaks were selected for labeling by dragging to acquire the wave numbers as well as the transmittance. The generated and labeled peaks were saved and printed. The absorbance spectra were acquired over a range of $400-4000 \mathrm{~cm}^{-1}$ using DTGS detector.

\section{Scanning Electron Microscope (SEM)}

The micro grain images of the prepared composite propellants were carried out using Phenomenon PROX with model number 4.5.3. Samples were pulverized to particle size of about 0.15 micron (100mesh) separately using Jaw Crusher. Exactly $0.5 \mathrm{~g}$ of the pulverized sample was smeared on the stud housing the double adhesive carbon. The sample STUD was placed in the sample holder connected to the sample port which was introduced to the machine and the chamber was closed. The sample was run for 5 seconds, and a prompt sound signified the sample was ready for imaging. The images were adjusted for sharpness, necessary zooming and refocusing. The resultant images formed were saved automatically and printed.

\section{Differential Scanning Calorimeter (DCS)}

Exactly $0.5 \mathrm{~g}$ of the samples were measured into crucibles and introduced into the sample holder compartment of the DSC machine (Model DSC $2 *$ E MERTTNER TELEDO) and the chamber was closed. The samples were run between $30-500^{\circ} \mathrm{C}$ for the thermal analysis giving the transition phase, endothermic and exothermic readings. The results (graphic) were printed by the print-out device of the machine.

\section{ROCKET DESIGN}

A full length of PVC pipe was cut to the length of $300 \mathrm{~mm}$, with diameter of $48 \mathrm{~mm}$. This is in line with the rocket tube diameter system. The fin diameter for the rocket was obtained using aluminum sheet of $0.5 \mathrm{~mm}$ thickness which was cut into a required measurement of $50 \times 48 \mathrm{~mm}$.

A cone height of $50 \mathrm{~mm}$ diameter by $40 \mathrm{~mm}$ was obtained by using Plastic of Paris (POP) which was molded using a mold to the required cone shape.

After the selection of propellant samples, the propellant formulated using the plant biomass AMIGA, BMIGA, CMIGA, APAS and CCAS were according to their ratios used. The samples, were measured to $300 \mathrm{~g}$ each and formed into the hallow tube geometry (shaped by compressing them). This was made into 6 different geometric according to the samples ID selected. The selection was done based on the Differential Scanning Colorimeter research with the ones having higher heat values. After the compression, it was then allowed to dry at room temperature. The ignition system was designed using a cable with the 2 ends soldered to the filament containing an ignition charge which it is thereafter connected to a match composition with power source (battery) which allowed the flow of current that was to ignite the propellants. 
Table 1 Sample Codes and their Ratios

\begin{tabular}{|l|l|l|}
\hline S/N & FORMULATED SAMPLE WITH STARCH & FORMULATED SAMPLE WITH GUM ARABIC \\
& BINDER CODE & $\begin{array}{l}\text { BINDER CODE } \\
(\mathbf{c})\end{array}$ \\
\hline $\mathbf{( a )}$ & $(\mathbf{b})$ & ACAGA \\
\hline 2. & BCAS & BCAGA \\
\hline 3. & CCAS & CCAGA \\
\hline 4. & AMIS & AMIGA \\
\hline 5. & BMIS & BMIGA \\
\hline 6. & CMIS & CMIGA \\
\hline
\end{tabular}

Key $\quad \underline{\text { Samples Used }}$

A - Ratio - 65:20:12:3 (Tenny, 1981) CA - Cassava Stem

B - Ratio - 80:16:2:2 (Cohen, 1981) MI - Millet stalk

C - Ratio - 85:10:4:1 (Proposed)

S - Starch Binder

GA - Gum Arabic Binder

\section{RESUlT AND DisCUSSION}

Physical Properties of Charred Unformulated Samples

The unformulated charred samples obtained were physically observed to be solid black powder with porous patches on the surface, and dark brownish.

Physical Properties of Formulated Sample

The formulated samples obtained exhibited a homogenous powdered form, black grayish with white patches.

\section{PHYSICAL CHARACTERISTICS}

The unformulated charred samples obtained were solid black powder with porous white patches on their surfaces, dark brownish and soft. While the formulated samples obtained were homogenous powdered form, black greyish with white patches.

\section{FTIR ANALYSIS}

The results obtained for the cassava stem with codes ACAS, BCAS and CCAS (Fig. 1) representing different ratios of A:B:C and ACAGA, BCAGA and CCAGA (Fig. 2) has exhibited $\mathrm{N}-\mathrm{H}, \mathrm{O}-\mathrm{H}, \mathrm{C}-\mathrm{O}$ and $\mathrm{C}-\mathrm{H}$ vibrational stretchings in the range of $3196.2 \mathrm{~cm}^{-1}-3207.4 \mathrm{~cm}^{-1}, 3660.2$ $\mathrm{cm}^{-1}-3809.3 \mathrm{~cm}^{-1}, 1041.5 \mathrm{~cm}^{-1}-1561.8 \mathrm{~cm}^{-1}, 10411.5 \mathrm{~cm}^{-1}$ $-1043.7 \mathrm{~cm}^{-1}$ and $713 \mathrm{~cm}^{-1}-825.6 \mathrm{~cm}^{-1}$ respectively, except for $\mathrm{O}-\mathrm{H}$ vibrational stretching which ACAGA, BCAGA and CCAGA did not exhibit, which could be as result of the gum arabic binder used.The millet stem with codes AMIS, BMIS and CMIS (Fig 3) that represents different ratios A:B:C and AMIGA, BMIGA and CMIGA (Fig 4) exhibited different stretching vibrations such as $\mathrm{C}=\mathrm{O}, \mathrm{N}-\mathrm{O}, \mathrm{C}-\mathrm{H}, \mathrm{O}-\mathrm{H}$, and $\mathrm{N}-\mathrm{H}$ at spectral range of $1761.2 \mathrm{~cm}^{-1} 1684 \mathrm{~cm}^{-1}, 1559 \mathrm{~cm}^{-1}$ $1399.6 \mathrm{~cm}^{-1}, 825 \mathrm{~cm}^{-1}-713 \mathrm{~cm}^{-1}, 3855.4 \mathrm{~cm}^{-1}-3649.1 \mathrm{~cm}^{-1}$

and $3229.7 \mathrm{~cm}^{-1}-3054.6 \mathrm{~cm}^{-1}$.. These spectral values indicated the presence of Esters, Alcohol, Nitro group, Amines which could be as result of the presence of AN, Carbon, Sulphur and the binders used. This results agrees with the study of Kangawaet $a l^{7}$ where they detected Isothiocynate at $1700 \mathrm{~cm}^{-1}$, azido groups at $2106 \mathrm{~cm}^{-1}, \mathrm{O}-\mathrm{H}$ at $3300 \mathrm{~cm}^{-1}$ and $\mathrm{N}-\mathrm{H}$ at $3364 \mathrm{~cm}^{-1}$. All these where obtained as a result of presence of poly AMMO/BAMO binders, AN and Polyurethane.

\section{Scanning Electron Microscope (SEM)}

The formulated cassava stalk sample with codes (ACAS, BCAS, CCAS, ACAGA, BCAGA and CCAGA) exhibited morphological characteristics of honey comb like shape, rhombic shape white uneven spherical shape and scraggy as indicated in Fig 5 and Fig 4.6. The morphology exhibited by the formulated samples is slightly the same which could be as a result of same plant biomass used as a source of carbon. These images and dimensions observed were within the ranges reported by Anniyappanet $a l^{8}$ in synthesis and characterization of 1,1 diamino 2,2 dinitroethylene.

The formulated millet stalk sample with codes (AMIS, BMIS, CMIS, AMIGA, BMIGA and CMIGA) exhibited a morphology of fiber like, scraggy with white substance unevenly spread, honey comb with benzene like ring linked to one another with open holes and porous as indicated in Fig 8 and Fig 7. The clusters displayed by the entire samples showed that the biomass had embedded the sulphur and starch. The images and dimensions observed in this study were within the ranges observed by Donovan et $a l^{9}$ in his study of characterization of propellant materials. 


\section{Agilent Technologies}

Sample ID:DANLADI HASSAN ACAS 65- 20-12-3

Method Name:Transmittance

Date/Time:2018-11-26T06:09:31.721-08:00

File Location:C:|Program Files\Agilent|MicroLab PC|Results\DANLADI HASSAN ACAS 65- 20-123_2018-11-26T06-09-31.a2r

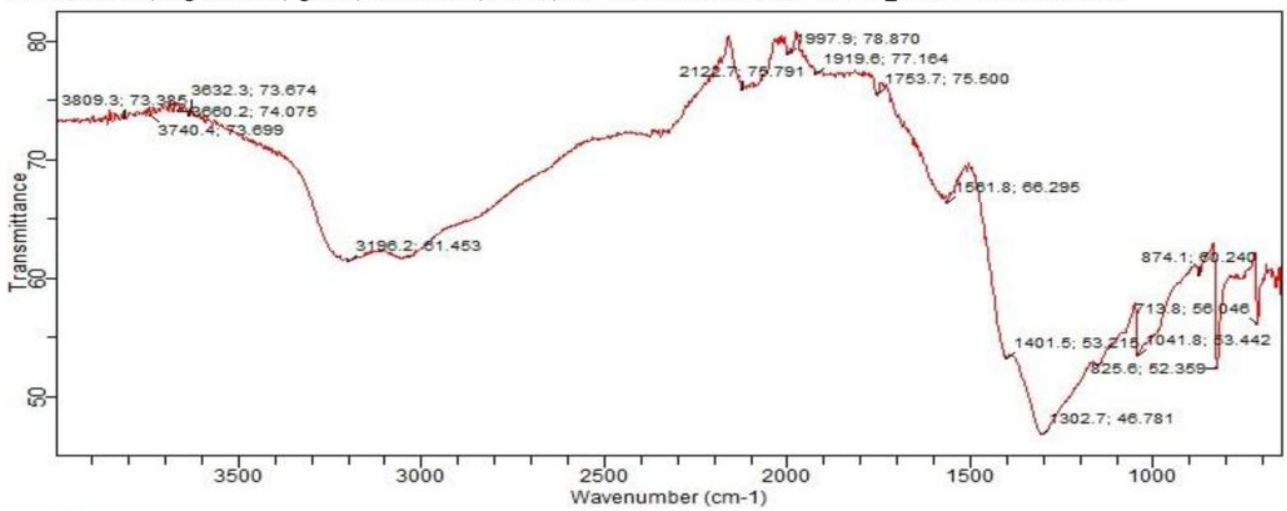

\section{Agilent Technologies}

Sample ID:DANLADI HASSAN BCAS 80-16-2-2

Date/Time:2018-11-26T06:54:32.473-08:00

Method Name:Transmittance

File Location:C:|Program Files\Agilent|MicroLab PC\Results\DANLADI HASSAN BCAS 80-16-22_2018-11-26T06-54-32.a2r

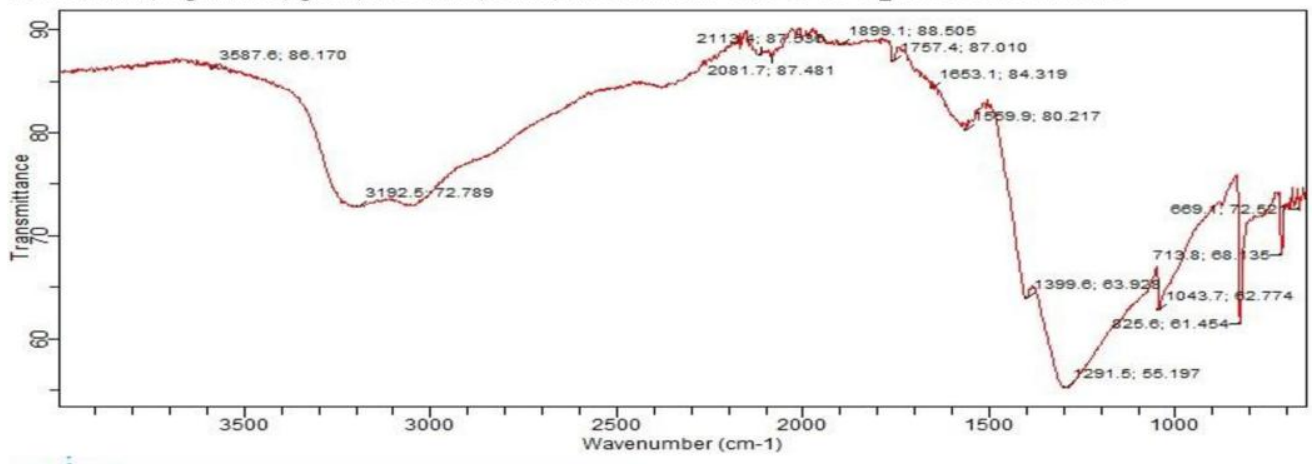

\section{Agilent Technologies}

Sample ID:DANLADI HASSAN CCAS 85- 10- 4-1

Method Name:Transmittance

Date/Time:2018-11-26T06:42:32.08-08:00

File Location:C:|Program Files\Agilent|MicroLab PC\Results\DANLADI HASSAN CCAS 85-10-41_2018-11-26T06-42-32.a2r

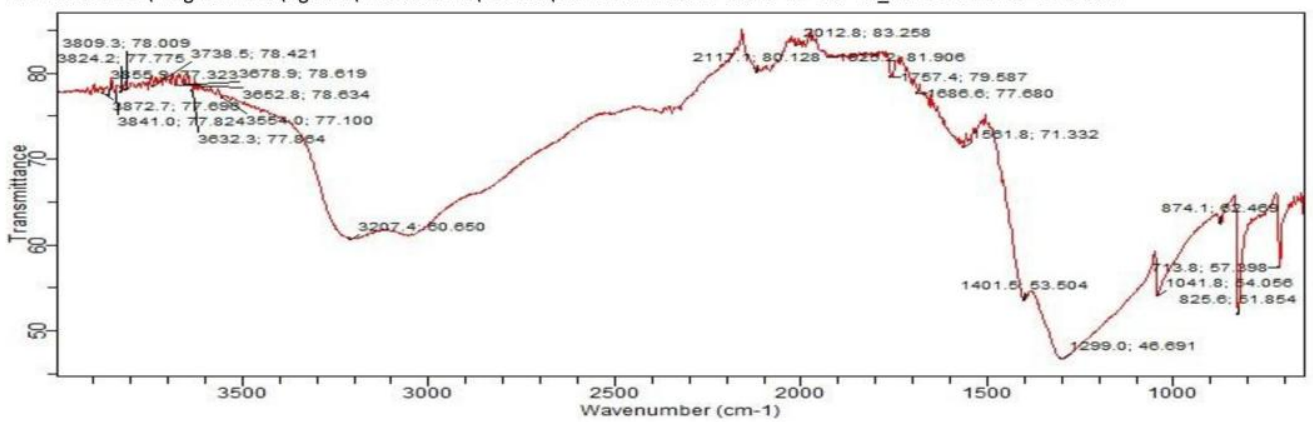

Fig 1: FTIR Spectra of Composite Propellant Samples ACAS, BCASand CCAS. 


\section{Agilent Technologies}

Sample ID:DANLADI HASSAN ACAGA 65-20- Method Name:Transmittance12-3

Date/Time:2018-11-26T07:55:05.319-08:00

File Location:C:|Program Files\Agilent|MicroLab PC\Results\DANLADI HASSAN ACAGA 65-20-123_2018-11-26T07-55-05.a2r

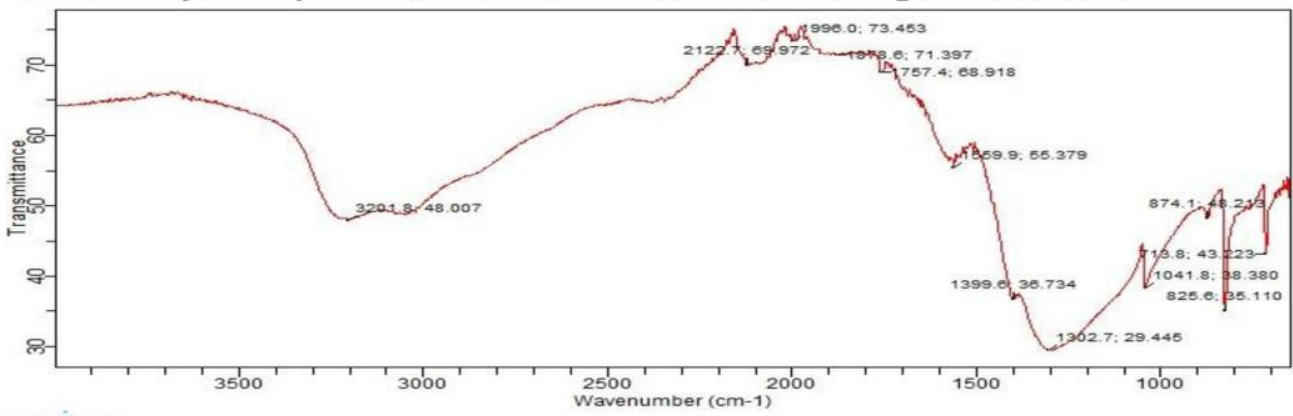

Agilent Technologies

Sample ID:DANLADI HASSAN BCAGA 80-16-2- Method Name:Transmittance 2

Date/Time:2018-11-26T07:08:44.562-08:00

File Location:C:|Program Files\Agilent|MicroLab PC\Results\DANLADI HASSAN BCAGA 80- 16-22_2018-11-26T07-08-44.a2r

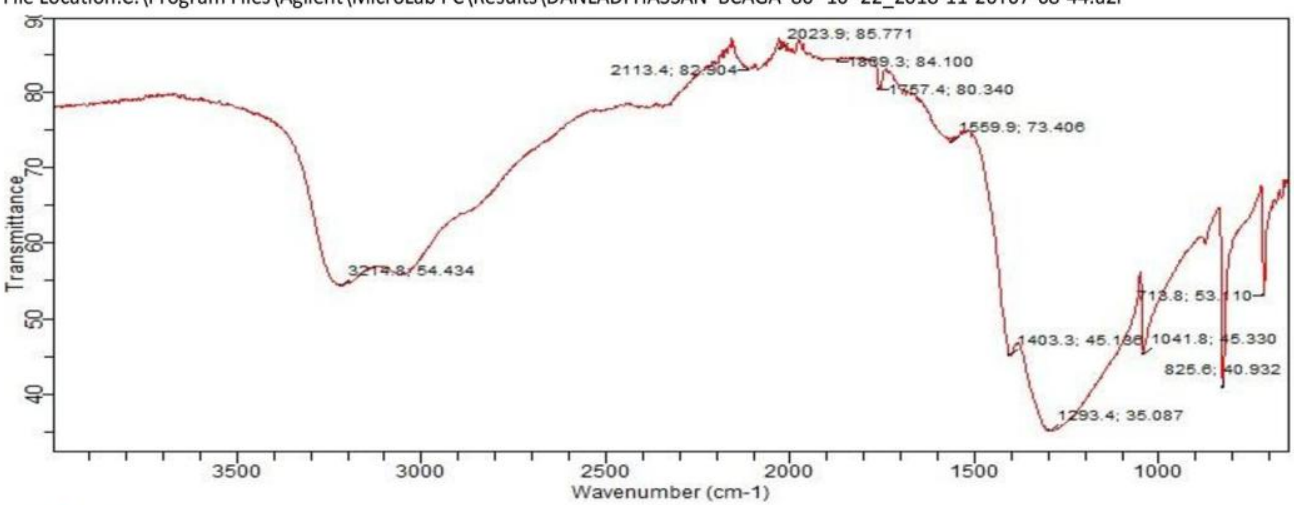

\section{Agilent Technologies}

Sample ID:DANLADI HASSAN CCAGA 85-10- 4- Method Name:Transmittance 1

Date/Time:2018-11-26T06:32:10.637-08:00

File Location:C:|Program Files\Agilent|MicroLab PC\Results\DANLADI HASSAN CCAGA 85- 10- 41_2018-11-26T06-32-10.a2r

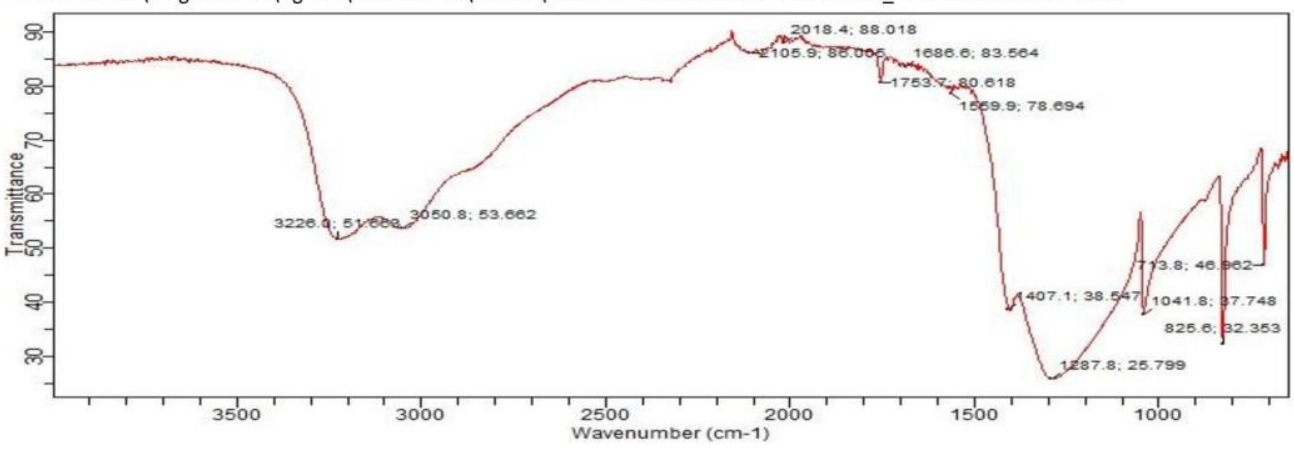

Fig 2: FTIR Spectral of Composite Sample of ACAGA, BCAGA and CCAGA 
Formulation and Characterization of Composite Propellants from Cassava Stem and Millet Stalk

\section{Agilent Technologies}

Sample ID:DANLADI HASSAN AMIS 65- 20-12-3

Method Name:Transmittance

Date/Time:2018-11-26T07:40:12.093-08:00

File Location:C:|Program Files\Agilent|MicroLab PC|Results\DANLADI HASSAN AMIS 65- 20-123_2018-11-26T07-40-12.a2r

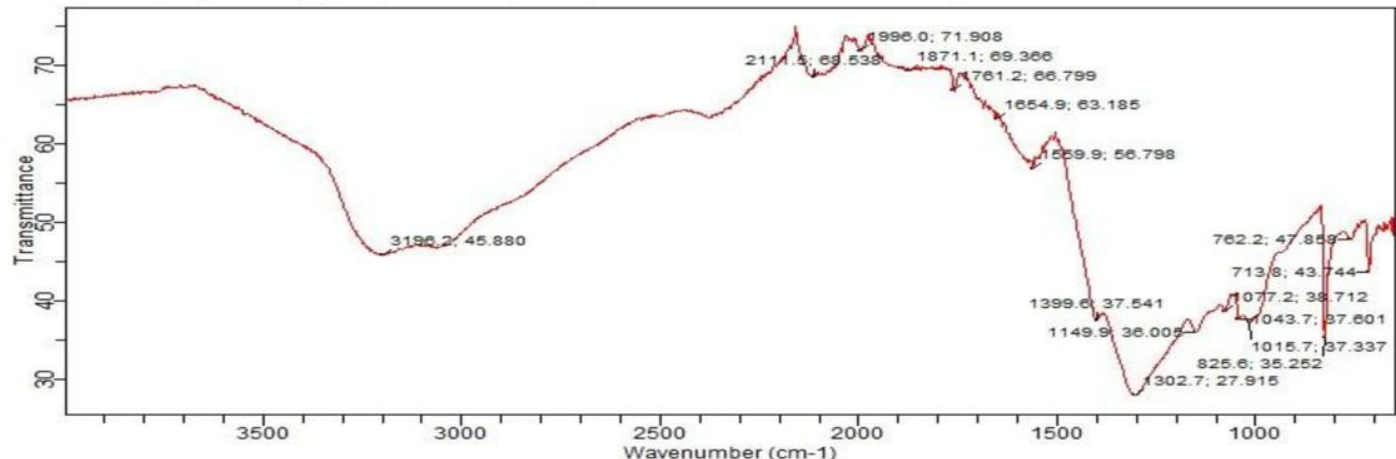

\section{Agilent Technologies}

Sample ID:DANLADI HASSAN BMIS 80-16-2-2

Date/Time:2018-11-26T07:00:55.906-08:00

Method Name:Transmittance

File Location:C:|Program Files\Agilent|MicroLab PC\Results\DANLADI HASSAN BMIS 80- 16-22_2018-11-26T07-00-55.a2r

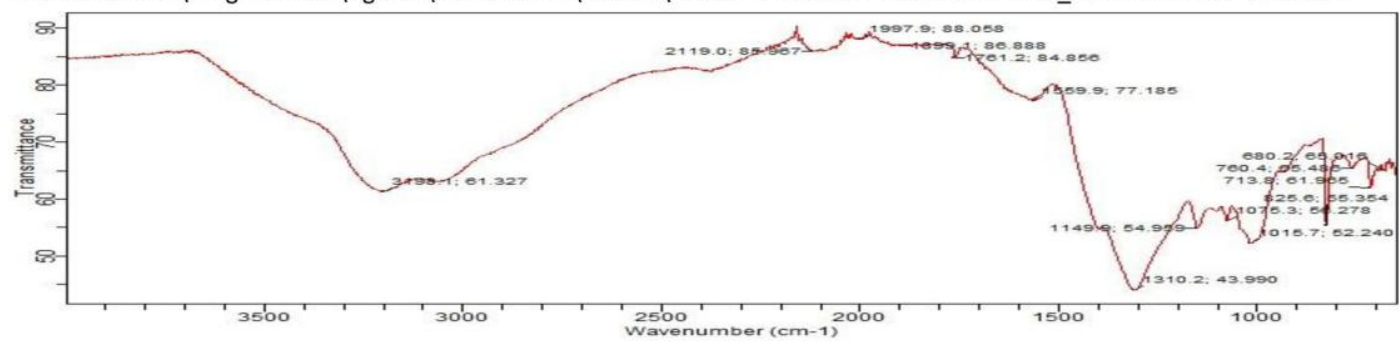

\section{Agilent Technologies}

Sample ID:DANLADI HASSAN CMIS 85-10-4-1

Method Name:Transmittance

Date/Time:2018-11-26T06:02:43.687-08:00

File Location:C: |Program Files\Agilent|MicroLab PC|Results\DANLADI HASSAN CMIS 85-10-4-1_201811-26T06-02-43.a2r

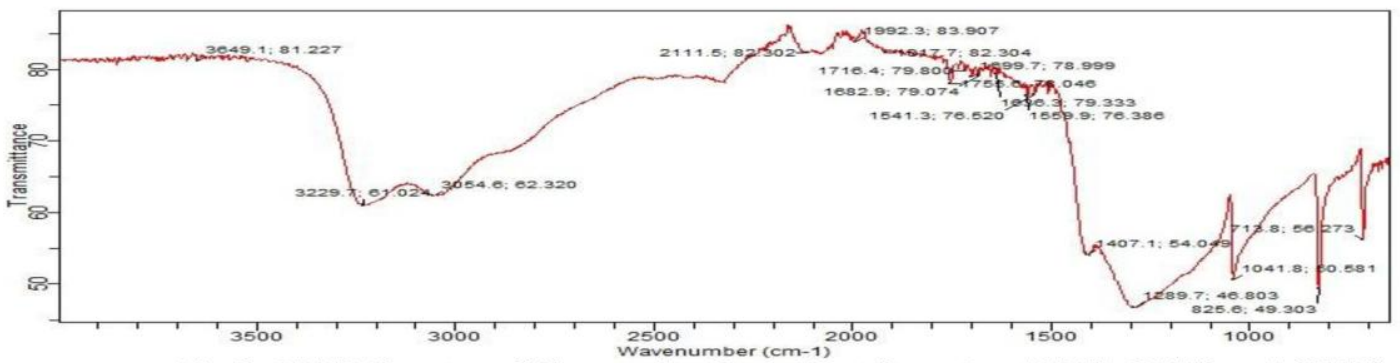

Fig 3: FTIR Spectra of Composite Propellant Samples AMIS, BMIS and CMIS. 


\section{Agilent Technologies}

Sample ID:DANLADI HASSAN AMIGA 65-20-

12-3

Method Name:Transmittance

Date/Time:2018-11-26T07:41:44.851-08:00

File Location:C:\Program Files\Agilent|MicroLab PC\Results\DANLADI HASSAN AMIGA 65- 20-123_2018-11-26T07-41-44.a2r

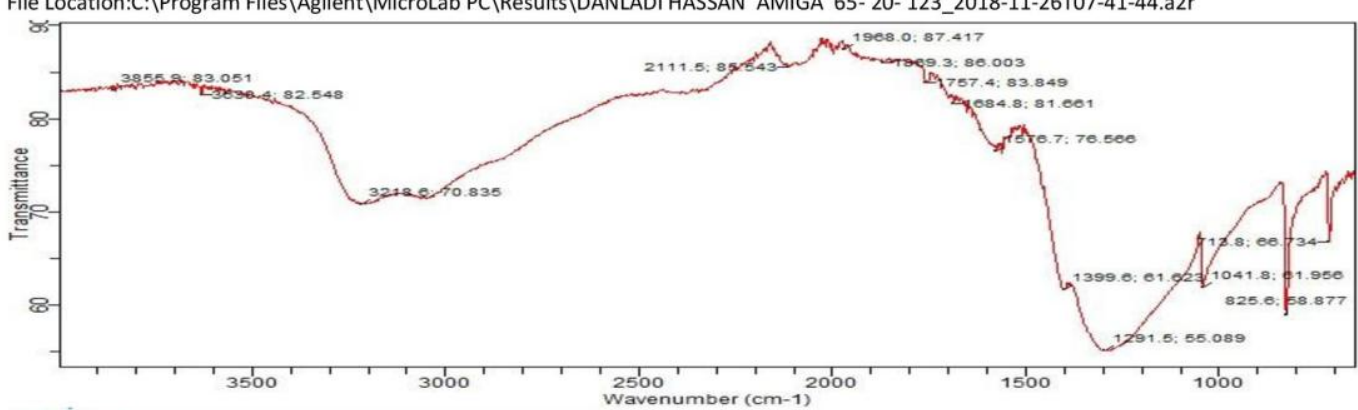

\section{Agilent Technologies}

Sample ID:DANLADI HASSAN BMIGA 80-16-2

Method Name:Transmittance 2

Date/Time:2018-11-26T07:13:59.901-08:00

File Location:C:\Program Files\Agilent\MicroLab PC\Results\DANLADI HASSAN BMIGA 80- 16- 22_2018-11-26T07-13-59.a2r

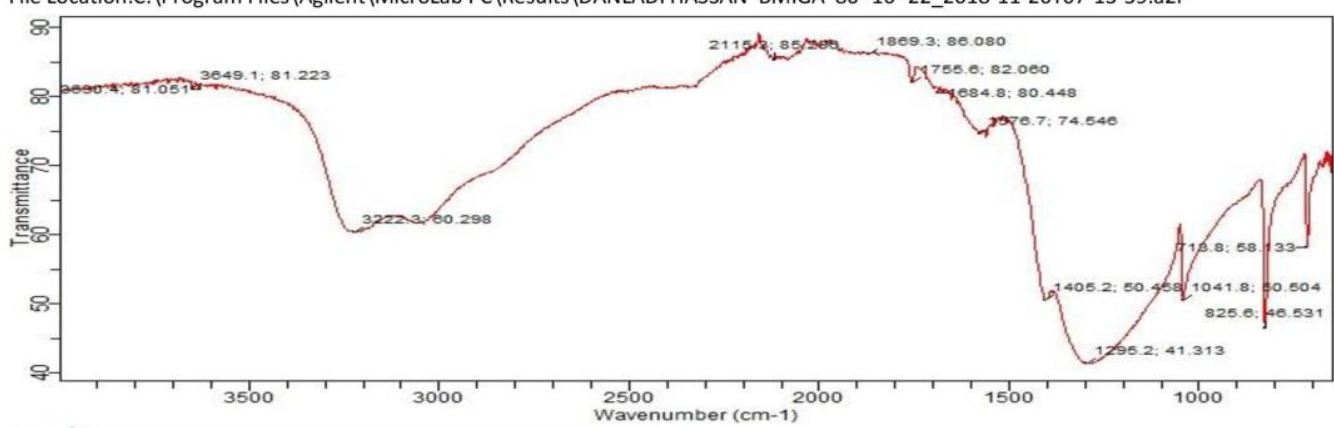

\section{Agilent Technologies}

Sample ID:DANLADI HASSAN CMIGA 85- 10- 4- Method Name:Transmittance 1

Date/Time:2018-11-26T06:34:44.094-08:00

File Location:C:\Program Files\Agilent|MicroLab PC\Results\DANLADI HASSAN CMIGA 85- 10-41_2018-11-26T06-34-44.a2r

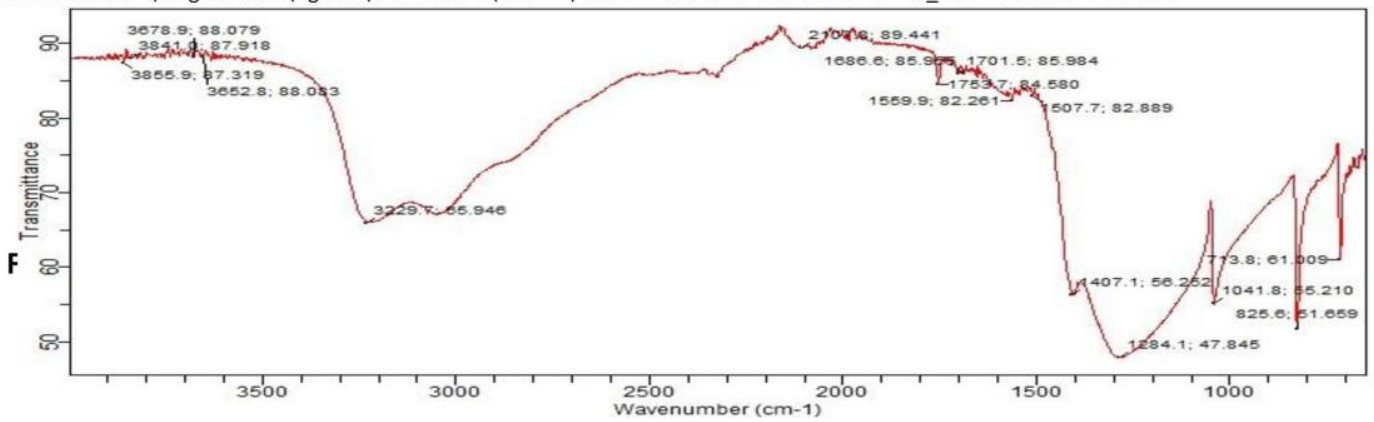

Fig 4: FTIR Spectral of Composite Sample of AMIGA, BMIGA and CMIGA 
Formulation and Characterization of Composite Propellants from Cassava Stem and Millet Stalk

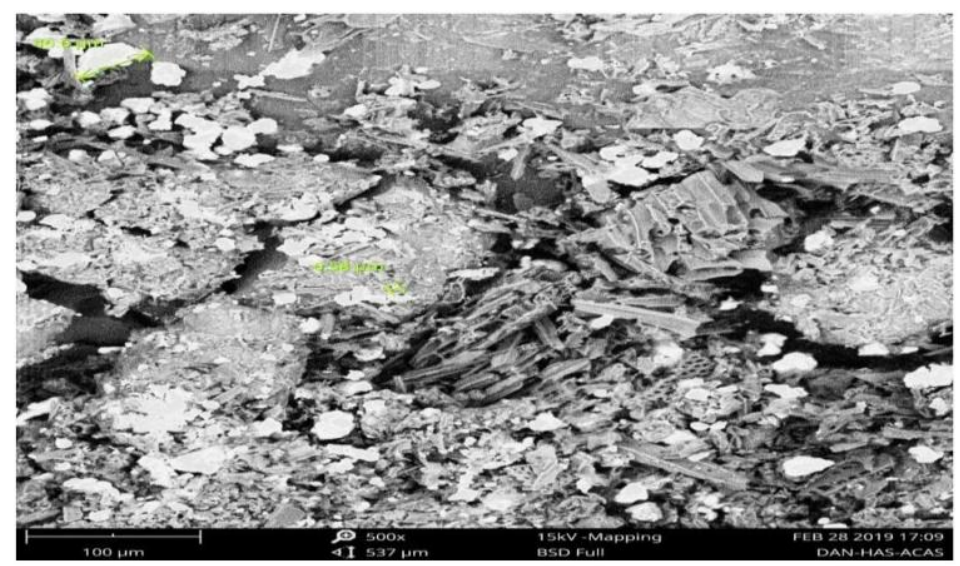

ACAS

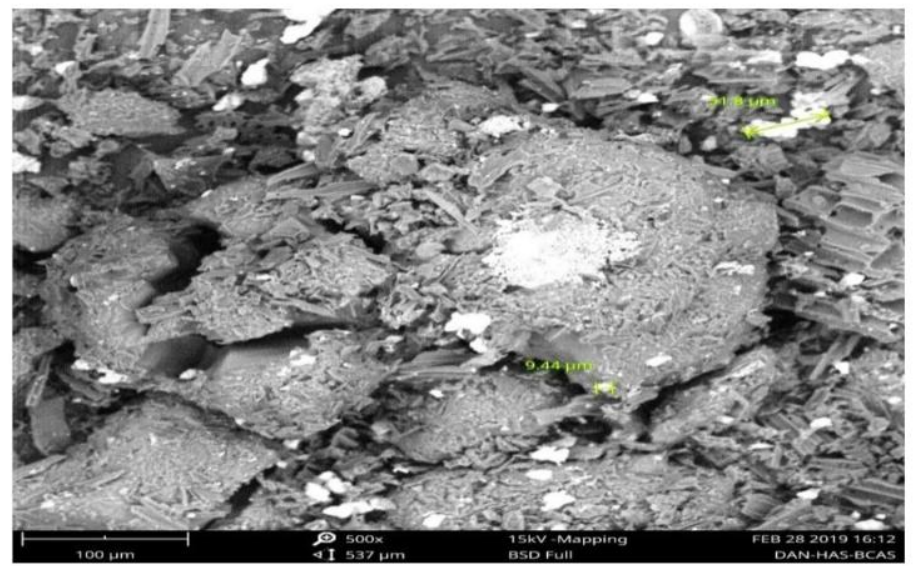

BCAS

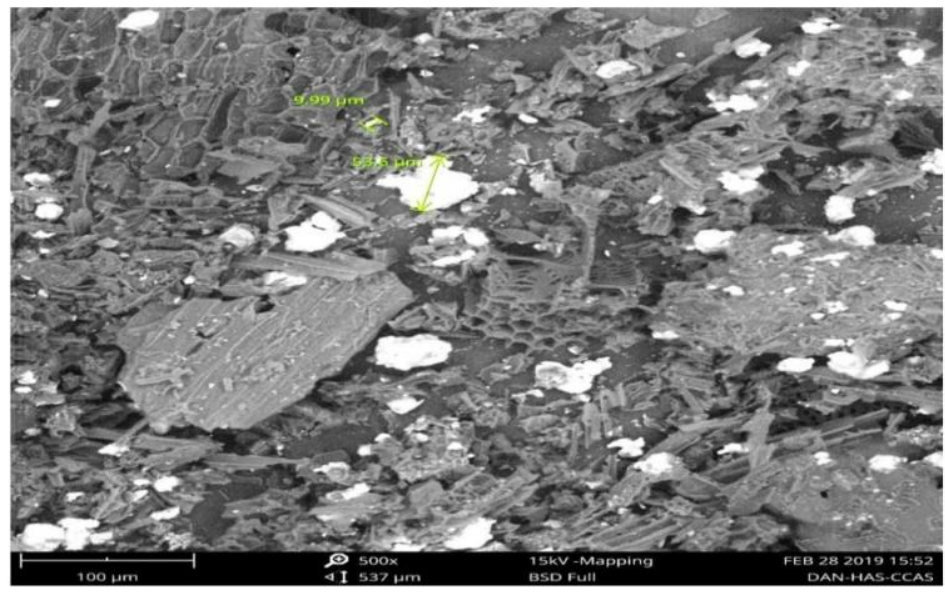

CCAS

Fig 5: SEM Image, Morphology of Samples ACAS, BCAS, CCAS 


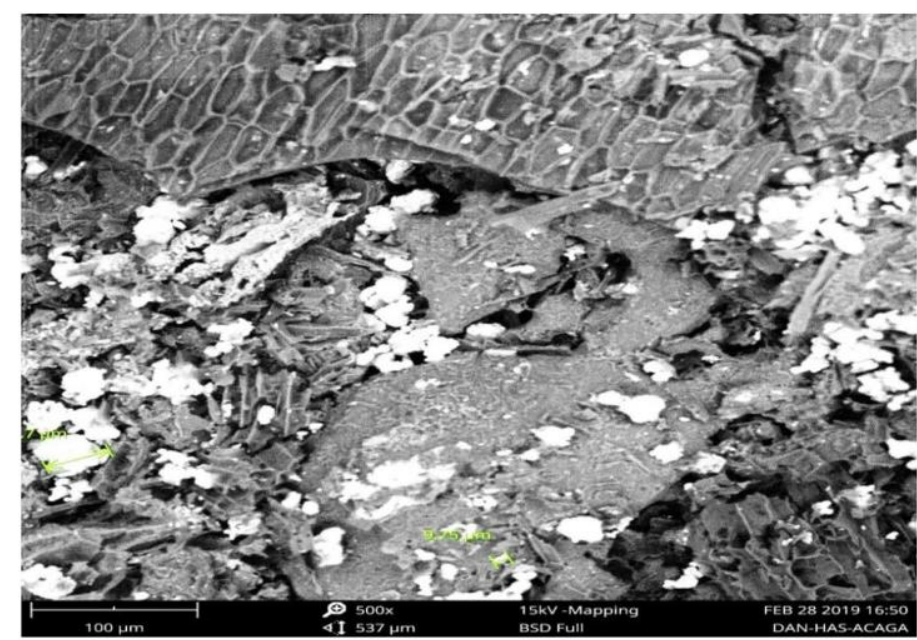

ACAGA

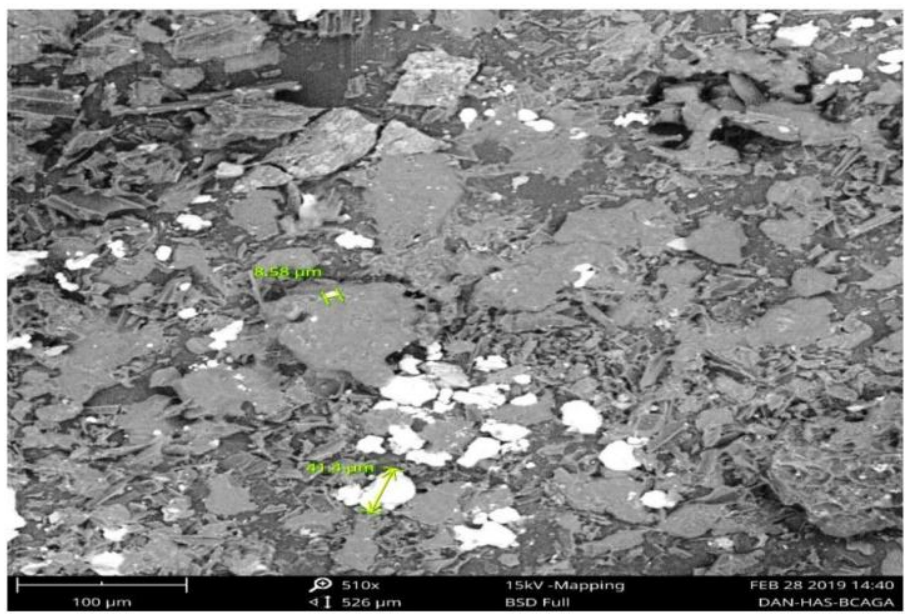

BCAGA

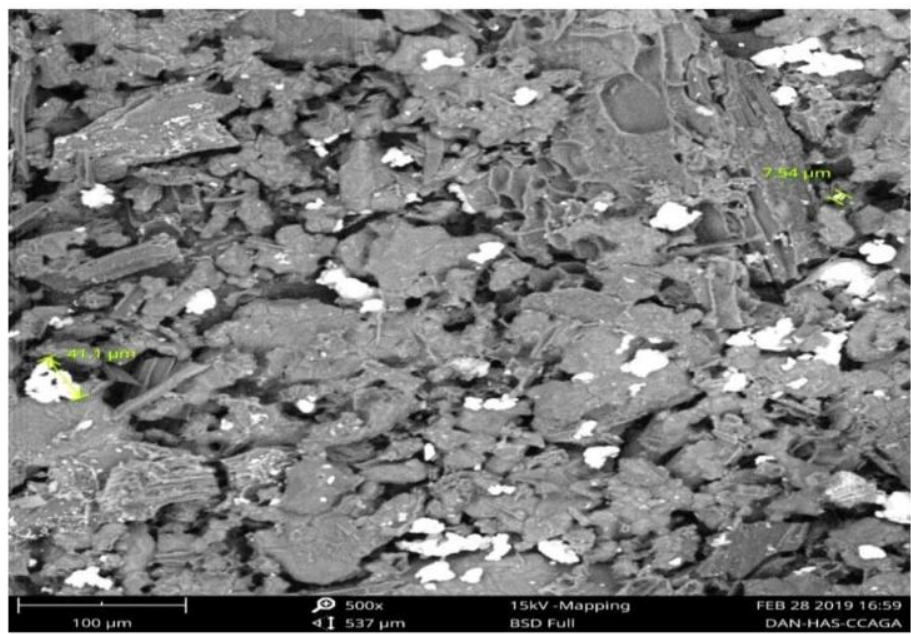

CCAGA

Fig 6: SEM Image, Morphology of Samples ACAGA, BCAGA, CCAGA 
Formulation and Characterization of Composite Propellants from Cassava Stem and Millet Stalk

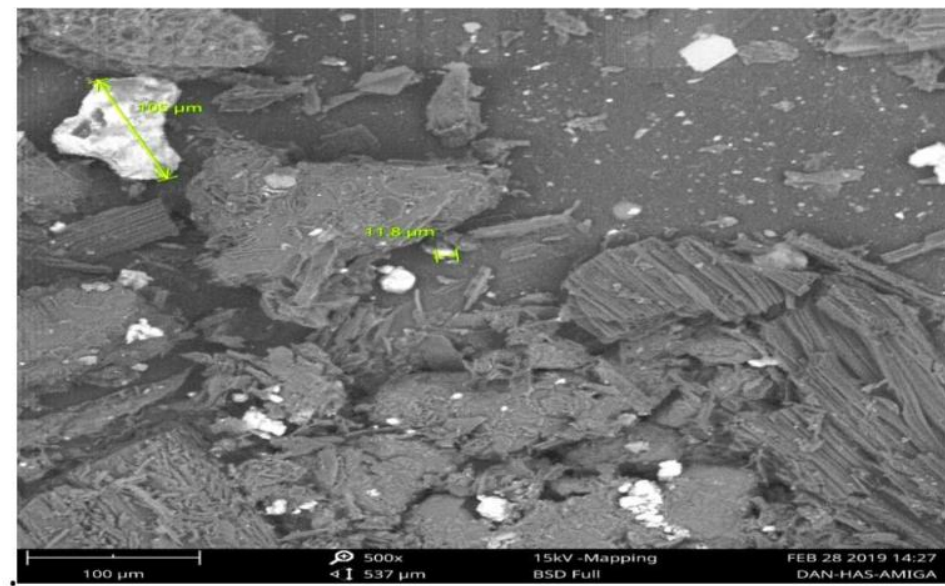

AMIGA

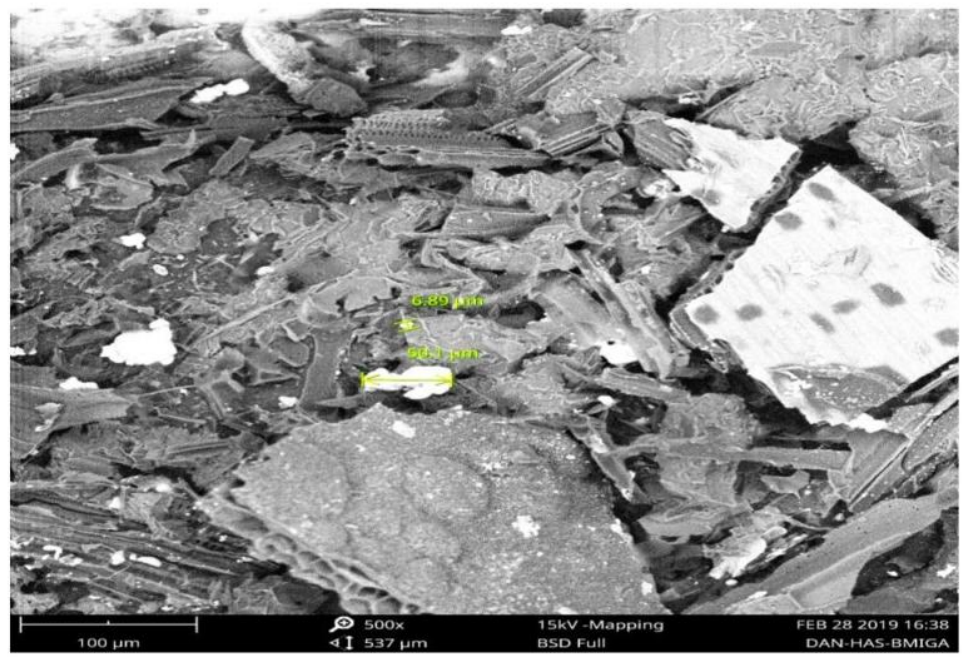

BMIGA

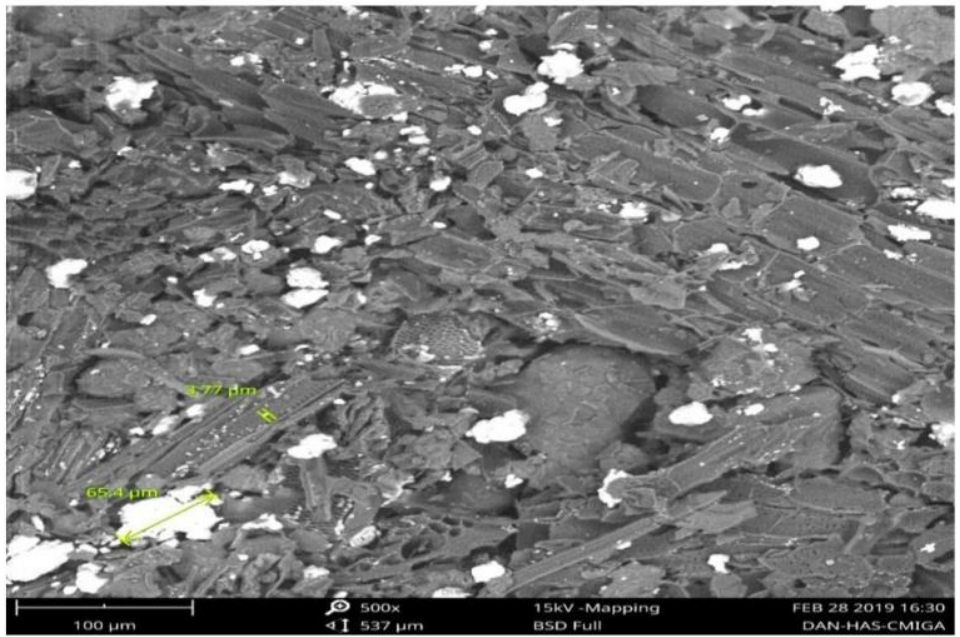

CMIGA

Fig 7: SEM Image, Morphology of Samples AMIGA, BMIGA and CMIGA 


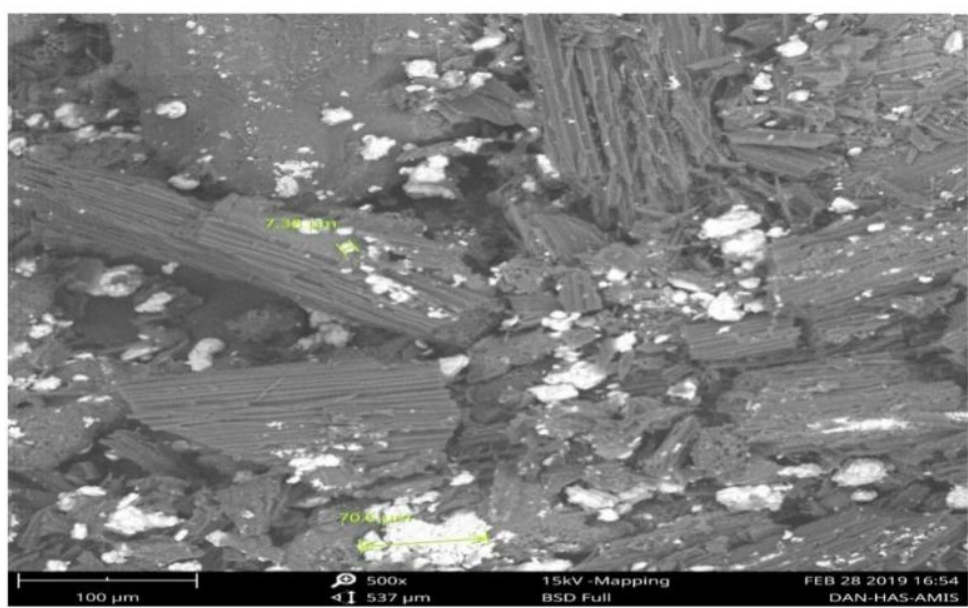

AMIS

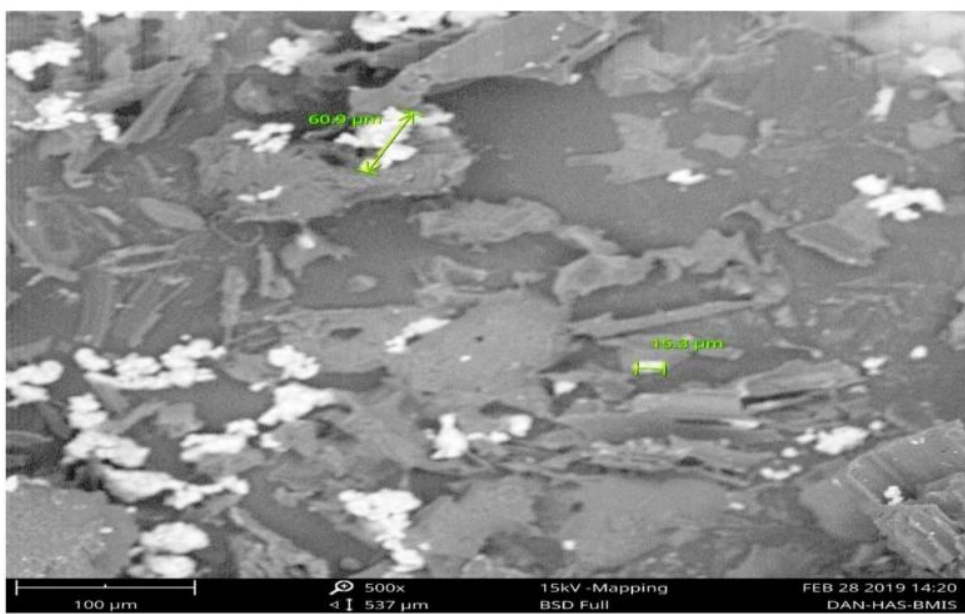

BMIS

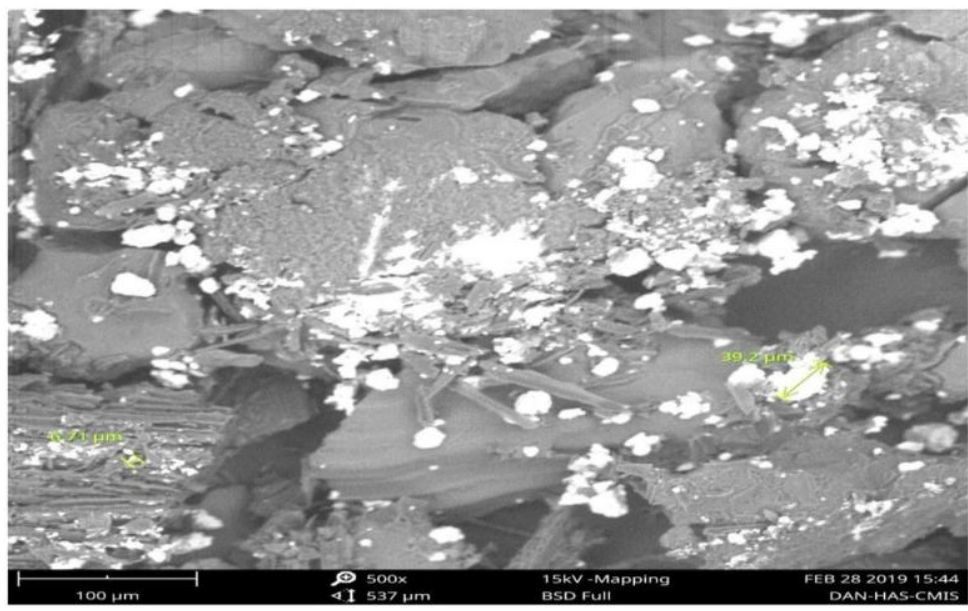

CMIS

Fig 8: SEM Image, Morphology of Samples AMIS, BMIS and CMIS 


\section{Differential Scanning Calorimeter (DSC)}

DSC curve (Fig: 9) displayed peak samples ACAS, BCAS and CCAS. The peaks are of endothermic temperature values of $120-168{ }^{\circ} \mathrm{C}$ indicating the phase change gradually melting from $120{ }^{\circ} \mathrm{C}$ and melted at $168^{\circ} \mathrm{C}$ before decomposing at the high peak of exothermic. The samples also displayed exothermic values of $216.13,202.25$ and $209.12{ }^{\circ} \mathrm{C}$ for ACAS, BCAS and CCAS respectively indicating the temperature at which they decomposed. While Fig 10 showed DSC peaks of ACAGA, BCAGA and CCAGA which exhibited an endothermic temperature values of $0-130,128$ 130 and $128-168{ }^{\circ} \mathrm{C}$, indicating the phase change, gradually melting from the low temperature to the high endothermic temperature and melted before decomposing at the high peak of exothermic. The samples also displayed an exothermic values of $205.94,202.59^{\circ} \mathrm{C}$ and $210^{\circ} \mathrm{C}$ which indicate the temperature at which they decomposed. This result can be compared with the work of Goncalveset al, ${ }^{10}$ who worked on three different composite propellants Ammonium Perchlorate $65 \%$ and Hydroxyl Terminated Poly Butadiene (HTPB) $15 \%$ ( FA), Ammonium Perchlorate $60 \%$ and Hydroxyl Terminated Poly Butadiene (HTPB) $18 \%(\mathrm{FB})$ and Ammonium Perchlorate $55 \%$ and Hydroxyl Terminated Poly Butadiene (HTPB) $20 \%$ (FC) using ammonium per chlorate where propellant $\mathrm{FA}$ and $\mathrm{FB}$ displayed an exothermic value of $330{ }^{\circ} \mathrm{C}$ and $\mathrm{FC}$ displayed $246{ }^{\circ} \mathrm{C}$ which are close to values reported in this study. These temperatures indicate the complete decomposition and combustion of the propellant used.

Sample AMIS, BMIS and CMIS in Fig 11 displayed an endothermic values of $0-91,40-128$ and $-170{ }^{\circ} \mathrm{C}$ indicating the phase change, gradually melting from the lower temperature and melted at the highest endothermic temperature before combustion at the high peak temperature of exothermic value of $128^{\circ} \mathrm{C}, 185.83^{\circ} \mathrm{C}$ and $188.90^{\circ} \mathrm{C}$ for AMIS, BMIS and CMIS while from Fig 12 shows DSC peaks of AMIGA, BMIGA and CMIGA which displayed an endothermic value of $130{ }^{\circ} \mathrm{C}$ and $170{ }^{\circ} \mathrm{C}$ for all the 3 samples. The entire three samples indicated a phase change gradually melting from the lower temperature and melted at the highest endothermic temperature of $170{ }^{\circ} \mathrm{C}$ before decomposing and combusting at the high peak temperature of exothermic value of $187.57,203.00$ and $195.85^{\circ} \mathrm{C}$ for AMIGA, BMIGA and CMIGA respectively. This also can exhibit same trend with work of Goncalveset al, ${ }^{10}$ who worked on three different composite propellants FA, FB and FC using ammonium per chlorate where propellant $\mathrm{FA}$ and $\mathrm{FB}$ displayed an exothermic value of $330{ }^{\circ} \mathrm{C}$ and $\mathrm{FC}$ displayed $246{ }^{\circ} \mathrm{C}$. These temperatures indicate the complete decomposition and combustion.

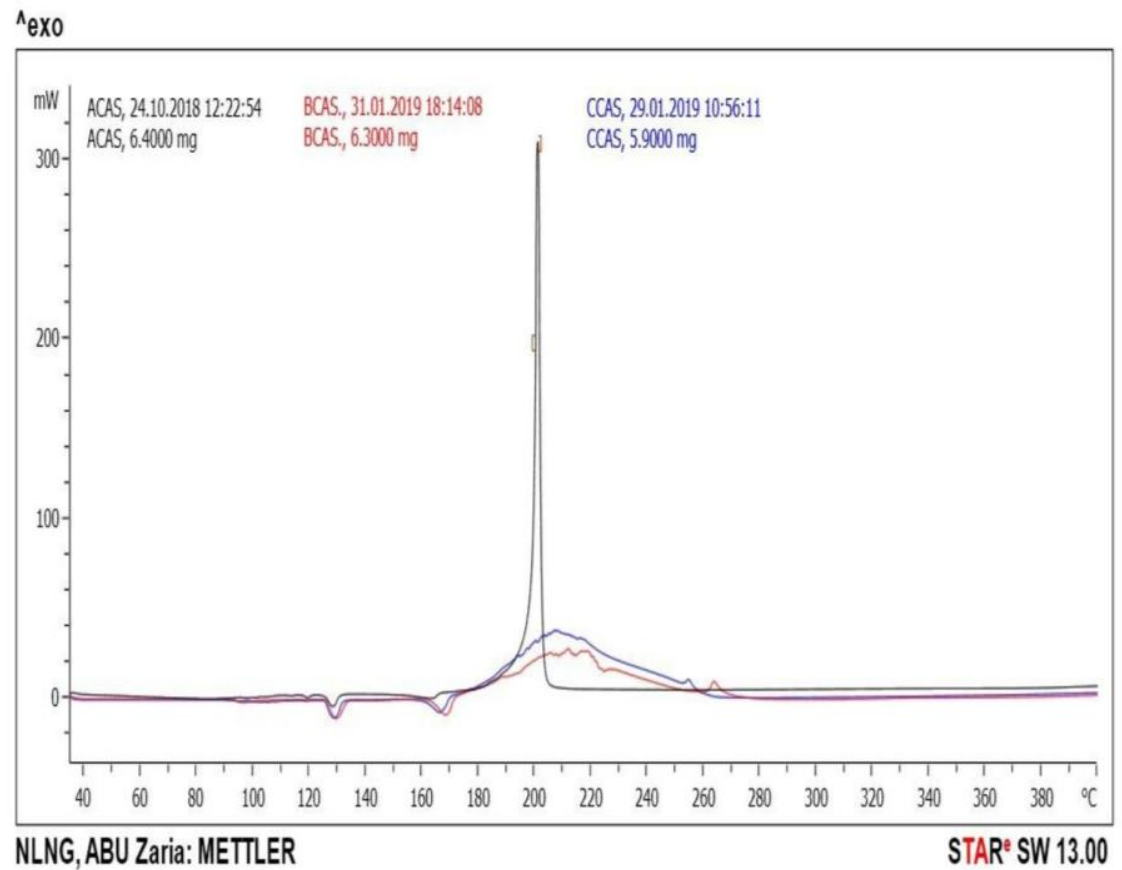

KEY: Black: ACAS, Red: BCAS, Blue: CCAS

Figure 9:Showing the DSC Curve of ACAS, BCAS and CCAS 


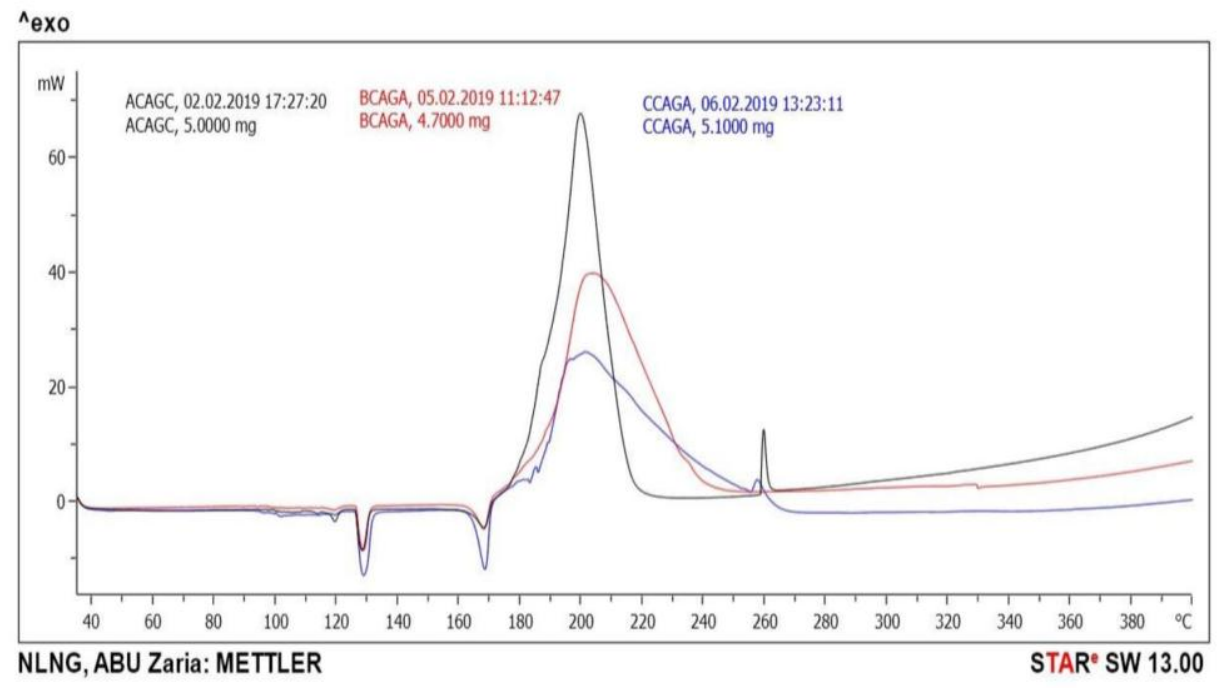

KEY: Black: ACAGA, $\quad$ Red: BCAGA, $\quad$ Blue: CCAGA

Figure 10: Showing the DSC Curve of ACAGA, BCAGA and CCAGA

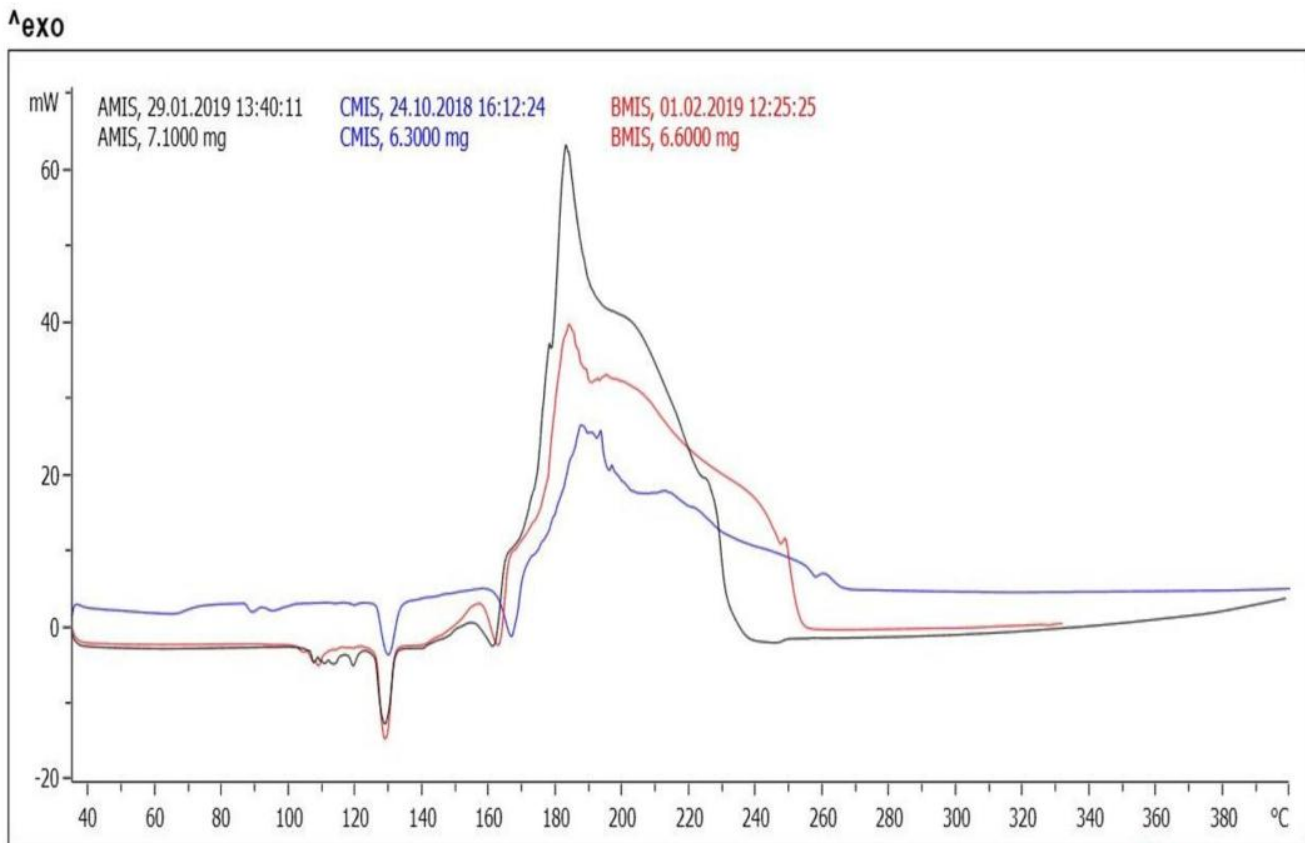

NLNG, ABU Zaria: METTLER

KEY: Black: AMIS,

Red: CMIS,

Blue: BMIS

Figure 11: Showing the DSC Curve of AMIS, BMIS and CMIS 


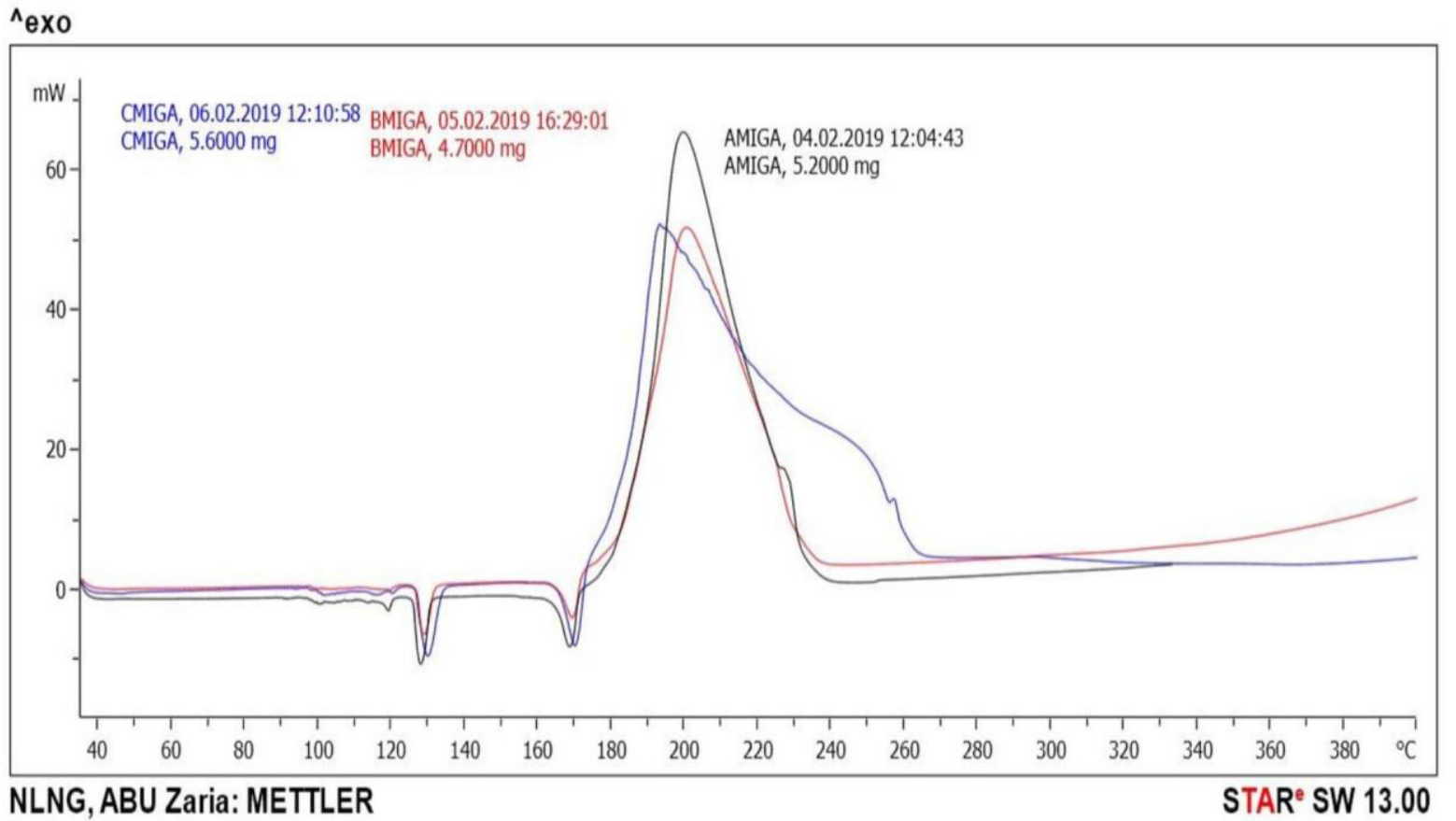

\section{KEY: Blue: CMIGA, Red: BMIGA, Black: CMIGA \\ Figure12: Showing the DSC Curve of AMIGA, BMIGA and CMIGA}

\section{ROCKET TESTING}

The rockets were tested at Research and Development Centre Field, Defence Industrial Corporation of Nigeria (DICON) Kadunain order to ascertain the performances of the propellants the result of testing revealed that ACAS, BCAGA, AMIS, BMIS and BMIGA did not project but burnt on the ground covering distances between $17 \mathrm{~m}-59 \mathrm{~m}$. However propellant CCAS projected distance of $480 \mathrm{~m}$ which gave a better performance due to the high exothermic values and porosity of the surface area of the propellant.

\section{CONCLUSION}

The unformulated charred samples were solid black powder with porous white patches, dark brownish and soft except palm kernel shell. The formulated samples were black grayish, homogenous powder while formulated samples from palm kernel shell was light grey The result of the study revealed that all formulated sample propellants exhibited different vibrational stretchings such as $\mathrm{N}-\mathrm{H}, \mathrm{O}-\mathrm{H}, \mathrm{C}=\mathrm{O}, \mathrm{N}-\mathrm{O}$ and $\mathrm{C}-\mathrm{H}$ among other vibrations. Additionally, the vibrational stretchings using different ratios $\mathrm{A}: \mathrm{B}: \mathrm{C}$ ranges from $1576.7 \mathrm{~cm}^{-1}-1302.7 \mathrm{~cm}^{-1}, 3738.5 \mathrm{~cm}^{-1}-3216.7 \mathrm{~cm}^{-1}$, $1761.2 \mathrm{~cm}^{-1}-1684 \mathrm{~cm}^{-1}, 1559 \mathrm{~cm}^{-1}-1399.6 \mathrm{~cm}^{-1}$ and $825 \mathrm{~cm}^{-1}$ - $713 \mathrm{~cm}^{-1}$. The spectra commonly indicated presence of Alcohols, Esters,Isothiocynate, Amines, Nitro groups, Alkenes among others. The morphology of the formulated samples observed using SEM were predominantly crater, honey comb, scraggy, flaky, rhombic shape and fiber like stripes entirely surrounded mostly by AN grain which were either large, small, dense spheroidal on the grain surface indicating composite formation. The dimensions of the formulated samples generally range from $105 \mu \mathrm{m}-3.77 \mu \mathrm{m}$. The clusters exhibited by all the formulated samples were indicative of homogenized composite mixture of $\mathrm{AN}$, biomass, surphurand the binders.

DSC analysis was carried out to evaluate the ignition temperature, melting point, phase change transition and decomposition temperatures. From the DSC results, the endothermic peaks range from $40-168^{\circ} \mathrm{C}$ while exothermic peaks range from $184-250^{\circ} \mathrm{C}$. The result indicates the burning rate ability of the propellants in space.

The rocket designed were tested at Research and Development Centre, DICON and the result of testing revealed that propellant with biomass CCAS gave better performances due to the distance covered of $480 \mathrm{~m}$. The result therefore indicated that the propellant were effective in projecting the rockets. Finally all the formulated propellant in this study can be used depending on the desired distance required.

\section{REFERENCES}

[1] Anniyappan M; Takwar M.B, Gore GM, Venogopalan S and Ghande B.R. (2006): Synthesis, Characterization and Thermolysis of 1, Diamno 1, 1 - dinitro ethylene (Fox-7) and its salt Journal of Hazardous Materials 137(2): 812-819

[2] Cohen, N.S., and Strand, L.D., (1981).“An Improved Model for the Combustion of AP Composite Propellants", paper 81-1553, 17th Propulsion Conference.

[3] Daintith, J. (2000). Oxford Dictionary of Chemistry, $4^{\text {th }}$ Ed. Oxford University Press, New York, USA. PP 146-149.

[4] Donovan, N., Leonard, G., Chandler, W. and Supapan, S., (2012). Characterization of Propellants Materials $\left(2^{\text {nd }}\right.$ ed. $)$. John Wiley \& Sons.DOI:1002/0471266965.com081.pub2

[5] Goncakves RFB, Rocco IAFF and Iha K. Thermal (2017) Thermal Decomposition Kinetics of Ages Solid Propellant Based on 
Ammonium Per Chlorate (AP/HIBP). 2013. Journal of INTECH Open Science.14:325-340

[6] Kangawa (2012): Thermal Decomposition of Ammonium per chlorate (AP) based composite propellant Vol 120;1 - 9.

[7] Kurva, R., Shekhar N. J., Swati, S.M.,andBikash, B., (2012). Development Of A Composite Propellant Formulation With A High Performance Index Using A Pressure Casting Technique , High Energy Materials Research Laboratory, Pune, 411021.

[8] Moulai, K.B., Mitche, L., Laurence, J., and Alain, D., (2016). Temperature Sensitivity of Propellant Combustion and Temperature Coefficient of Gun Performance.Central European Journal of Energetic Materials, 13(40:1005-1026

[9] Shalini C., and Pragnesh, N. D., (2014). Solid propellant AP/HTBP Composite Propellant Department of Chemistry, 370001 ,

[10] Tenny, L.D., (1981).The Chemistry of Powder and Explosives.Angrif Press, Las Vegas, Navada, 195-214, 256-267 